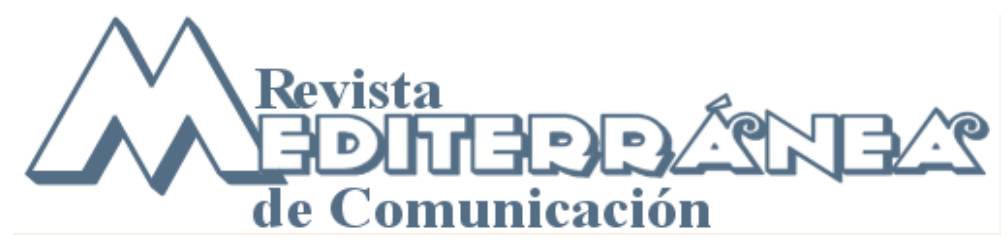

Año 1 (2010), pp. 195-212 ISSN 1989-872X

\title{
El espejo mágico: la sociedad española de la II República según la publicidad de la revista Crónica (1931-1936)
}

\section{The magic mirror: the Spanish company of the Republic II according to the advertising of the Chronic magazine (1931- 1936)}

\author{
Prof. Isabel M. González Mesa \\ Universidad Miguel Hernández. España. \\ i.gonzalez@umh.es
}

\begin{abstract}
Resumen
Conocer los contextos en los que se desenvuelve una determinada sociedad es fundamental para comprender las pautas que rigen el sector publicitario dentro de unas coordenadas espacio-temporales, pero también resulta interesante establecer el proceso inverso. Es decir, partir de la producción publicitaria para describir un determinado contexto social, conocer los factores que lo producen y qué propuesta de sociedad se desprende de ese discurso publicitario. En este trabajo se trata de describir el modelo de sociedad española durante el período de la II República basándose en el análisis de la publicidad insertada en Crónica, una revista de información general, durante dos períodos de quince semanas cada uno, en 1931 y 1936.
\end{abstract}

\section{Palabras clave}

Publicidad; prensa; sociedad española; Segunda República; España.

\section{Abstract}

The knowledge of the contexts in which a particular society develops itself becomes essential, in order to understand the norms that shape the advertising sector within a specific time and spatial framework, but it is also relevant to establish the opposite process. That is to say, the process of describing a particular social context from the advertising production, taking into account the factors that produce such a context, and the type of society which unfolds from such an advertising discourse. In this paper, we attempt to describe the model of the Spanish society during the II Republic, based on the analysis of the advertisements published in Crónica, a general news magazine, during two periods of fifteen weeks each, in 1931 and 1936. 


\section{Keywords}

Advertising, press, the spanish society, Second Republic, Spain.

Sumario: 1. Introducción. 2. La sociedad de la II República. 3. La profesionalización de la publicidad en España. 4. Las revistas como soporte publicitario 5. Metodología. 6. Resultados. 6.1. La salud. 6.2. La belleza. 6.3. El hogar, la familia y el trabajo. 6.4. Mujeres y hombres. 6.5. El ocio y la cultura. 6.6. La geografía de la publicidad. 7. Conclusiones. 8. Bibliografía.

Summary: 1. Introduction. 2. The society of the Second Republic. 3. The professionalization of advertising in Spain 4. Magazines as an advertising medium. 5. Methodology. 6. Results. 6.1. Health. 6.2. Beauty. 6.3. The home, family and work. 6.4. Women and men. 6.5. Leisure and culture. 6.6. The geography of advertising. 7. Conclusions. 8. Bibliography.

\section{Introducción}

El gran escaparate de la sociedad y la economía de un país es la publicidad que publican o emiten sus medios de comunicación. Muchos de los inmigrantes que llegan a las costas españolas procedentes de países subsaharianos vienen en busca de esa Europa rica que vende automóviles que conducen solos, electrodomésticos que hablan o familias en estado de felicidad permanente que crean "repúblicas independientes" en sus casas cada fin de semana. Como en el mito de la caverna de Platón, quizá la única realidad que percibamos de nosotros mismos sean las sombras que proyectamos y la publicidad es, sin duda, un inmenso proyector social. Sólo han evolucionado las herramientas.

La publicidad como expresión de la sociedad de masas es un fenómeno que hizo su aparición en España durante el primer tercio del siglo XX, con un auge espectacular durante los años que coincidieron con los gobiernos de la Segunda República hasta que la Guerra Civil puso un largo paréntesis en la consolidación de la llamada sociedad de consumo y por ende, en la madurez del ejercicio publicitario.

Conocer los contextos histórico, social, político y económico que envuelven a una determinada sociedad es básico para comprender las pautas por las que se rige el sector publicitario dentro de unas coordenadas espacio-temporales, pero también resulta no menos interesante establecer el proceso inverso. Es decir, partir de la producción publicitaria explicitada en cualquiera de sus soportes para describir un determinado contexto social, conocer los factores que lo producen y qué propuesta de sociedad refleja ese discurso publicitario.

Lejos de adentrarnos en esa batalla, hasta ahora estéril, sobre si la publicidad crea, recrea o refleja la realidad (Fagoaga y Secanella, 1984), nos situaremos en un punto intermedio en el que, sin desdeñar el poder reformador o deformador que la publicidad tiene sobre la realidad, tomaremos en consideración exclusivamente su función como espejo social. Coincidimos con Goffman (1991) en que existe una "identidad social virtual" que contrasta con otra "identidad social real". En ocasiones ambas pueden coincidir, mostrando así la veracidad de los estereotipos sociales, pero también pueden presentar realidades muy dispares entre sí. Para Susana de Andrés (2004: 19) "el anuncio no es sólo una propuesta comercial. Es un producto cultural y como 
tal asimila e interpreta su contexto (...) Su mensaje se crea por influencia social y para influir socialmente"

Atendiendo a esa definición trataremos de describir el modelo de sociedad española que se desprende del análisis de la publicidad insertada en una revista de información general, Crónica, durante dos períodos de quince semanas cada uno, en 1931 y 1936. La referencia temporal estudiada coincide con los meses previos a la instauración de la Segunda República y con los que precedieron al estallido de la Guerra Civil, un período de la historia de España especialmente relevante tanto en avances sociales como en la profesionalización del ejercicio publicitario.

\section{La sociedad española de la II República.}

La Segunda República constituye uno de los procesos históricos de mayor interés desde un punto de vista sociológico dado el importante reordenamiento político, social y cultural que supuso dentro de las estructuras decimonónicas españolas que no se correspondían con los avances sociales que se extendían de un lado al otro del Atlántico. Las innovaciones científicas y las revoluciones sociales se sucedían a destajo marcando un ritmo acelerado en el escenario internacional. Era un período de transición hacia la nueva sociedad de masas y de consumo y la España republicana no quería quedarse al margen.

Los partidos obreros y los sindicatos, espoleados por el triunfo de la revolución bolchevique fueron cobrando pujanza social y política conviviendo con unas fuerzas inmovilistas que defendían el orden económico y social establecidos (Otero, 2003). No obstante, a pesar de los esfuerzos realizados por parte de las élites intelectuales y políticas de izquierda para desarrollar una sociedad más igualitaria, España seguía siendo un país rural, con altos índices de analfabetismo, sobre todo femenino, y con unos valores patriarcales firmemente arraigados. El nuevo escenario social y político se quedó en un intento de modernización que hubiera permitido albergar sectores sociales más amplios donde habrían tenido cabida una cultura más liberal y tolerante (Alonso y Conde, 1994).

En 1930 el 60\% de los españoles vivía en poblaciones de menos de diez mil habitantes, aunque la tendencia apuntaba a un proceso de concentración urbana, fundamentalmente en ciudades como Madrid, Barcelona y las zonas costeras de Levante y el País Vasco (Zoido y Arroyo, 2003). En cuanto a los índices de alfabetización, la sociedad española alcanzó un avance espectacular coincidiendo con los gobiernos de la II República. Éste es un factor fundamental para entender el incremento experimentado por el sector publicitario en un soporte escrito, ya que la lectura se presentaba como un requisito básico para llegar a los potenciales consumidores.

A principios de la década de los treinta sólo el $55,7 \%$ de la población sabía leer y escribir y la diferencia entre hombres y mujeres era de un millón más a favor de los varones. En 1940, la población alfabetizada había crecido espectacularmente hasta el $77 \%$ aunque el índice de analfabetismo femenino seguía triplicando al masculino (De Gabriel, 1997). Recién iniciado el período republicano, el $47,2 \%$ del alumnado de las enseñanzas medias eran chicas y poco antes del estallido de la guerra la cifra se había elevado al 75\%. De 1931 a 1936, el número de universitarias creció desde el 6,1\% al 8,8\% (Núñez, 1989).

Pero si residir en un entorno urbano y estar alfabetizado constituían elementos importantes a la hora de conformar la incipiente sociedad de consumo, también lo era tener un trabajo que permitiera disfrutar de un cierto poder adquisitivo. En el período analizado, según los censos de 
población y encuestas de población activa del INE recogidos por Teresa Rubio (1990: 48), casi la mitad de la población ocupada se concentraba en el sector agrario, poco más del $25 \%$ en el industrial y apenas un $20 \%$ en el aún poco desarrollado sector servicios. El contexto internacional de crisis económica no favorecía la integración laboral femenina. A pesar de los avances en la emancipación de la mujer que lideraba una élite de políticas, profesoras, artistas y deportistas, el perfil de la trabajadora española continuaba siendo el de una mujer joven y soltera o el de una viuda que se veía en la necesidad de sustituir al cabeza de familia en la manutención del hogar.

La introducción de mejoras laborales como la subida de los salarios, la jornada laboral de ocho horas, la baja por maternidad o el derecho a vacaciones pagadas contribuyeron a generar una clase media de asalariados urbanos con mayor poder adquisitivo y más tiempo libre que pronto se convertirían en objetivo de los publicistas. No obstante, la descompensación existente entre el Estado, con una fuerte implicación en la modernización de las estructuras sociales, y la sociedad real, que caminaba a remolque de esas políticas avanzadas en materia socio-laboral, constituía un escenario paradójico en el que se debatía la España republicana

\section{La profesionalización de la publicidad en España.}

A lo largo de los años veinte las agencias de publicidad norteamericanas comenzaron a construir el discurso ideológico que dio origen, en parte, a la sociedad de consumo. La aplicación en la industria de los métodos taylorista y fordista fueron determinantes en la aparición del fenómeno del consumo de masas y la publicidad se convirtió en una efectiva herramienta en la búsqueda de nuevos mercados. En España, la aparición de las nuevas clases urbanas, el auge de los medios de comunicación de masas, el rápido crecimiento de la población alfabetizada y el carácter científico que había adquirido la publicidad abonaron el terreno para que los empresarios confiaran en esa nueva y compleja actividad socio-económica llamada publicidad.

La implantación de empresas extranjeras del sector automovilístico o de alimentación trajo consigo un importante impulso de las agencias de publicidad y al final de la II República se contabilizaban en España más de doscientas que daban trabajo a casi dos mil personas (Bravo, 2000). La profesionalización y pujanza económica del ejercicio publicitario en España también se evidencia con la aparición de un gran número de revistas de empresa, tanto de firmas internacionales (Paramount, Kodak o General Motors) como nacionales (Compañía Telefónica Nacional de España o Gal) que denotan la modernización publicitaria que se registró en España durante aquellos años, a la vez que un síntoma de la transformación socio cultural del país. (Rodríguez Martín, 2008). Especialmente relevante fue el caso de General Motors que pidió a sus publicistas un importante esfuerzo para identificar las peculiaridades de la sociedad de cada país donde se instalaba (Merron, 1999) y que a través de su revista de empresa y de sus intensas campañas publicitarias en la prensa española se convirtió en un referente de la época

Entre las agencias con más prestigio encontramos a Veritas que creó innovadoras campañas pedagógicas sobre higiene buco-dental como la del dentífrico Dens. O Publicitas, de origen suizo, que dio a conocer marcas tan populares en los años 30 como Camomila Intea, Calber o Gillette. Otras agencias del momento con gran proyección fueron la agencia Prado (Elixir Sainz de Carlos y cosméticos Vasconcel), la agencia Valor (Cafiaspirina y papel de fumar Bambú), la agencia Mercurio (Ambré Solaire, Maybelline) y Helios que gestionó marcas como los famosos Hipofosfitos Salud y los automóviles Ford y Renault. 
Durante la II República, la mayoría de la publicidad se dirigía a las clases medias que se habían enriquecido durante la I Guerra Mundial, al funcionariado que trabajaba para la Administración y a la incipiente clase obrera urbana que se beneficiaba de los avances sociales y salariales. Obviamente existían amplios sectores sociales ignorados por una publicidad que transmitía un estilo de vida asociada al lujo y a la que gustaba proyectar una imagen idílica de clases ricas y distinguidas aunque sólo fuese a través de una imitación fácil y con expresiones tópicas como "dama chic" o "for gentleman", utilizadas como muletillas lingüísticas de una élite que se autoproclamaba políglota (De Andrés, 2004).

\section{Las revistas como soporte publicitario.}

Las revistas de información general o magazines fueron el medio más utilizado por las agencias de publicidad de la época para insertar sus anuncios. Eran revistas de amplia divulgación, con ediciones semanales y precios asequibles, entre 20 y 40 céntimos, que presentaban formatos modernos, con ilustraciones mediante huecograbado entre las que destacaba la revista de información general Crónica que era una de las preferidas por las mujeres para informarse por la gran abundancia de ilustraciones, contenidos y por su lenguaje ameno y, en muchas ocasiones, hasta frívolo.

Junto a Crónica lideraban el panorama de la prensa gráfica semanal otras revistas como Estampa, revista gráfica y literaria que competía con Crónica en contenidos, formato y precio, aunque con un tono más femenino y conservador, y Blanco y Negro, otra de las grandes del sector, del grupo Prensa Española, mucho más conservadora y elitista que las dos anteriores, aunque esta última atravesó un período de inestabilidad durante los años de la República y su publicación fue intermitente.

La revista Crónica, objeto de nuestro estudio, se enmarcaba dentro del tipo de prensa republicana, muy popular entre el colectivo femenino y una de las preferidas por los anunciantes y las agencias para insertar la publicidad. Integrada dentro del grupo editorial Prensa Gráfica, que publicaba otras revistas como La Esfera, Mundo Gráfico o Cinegramas, Crónica salía los domingos a un precio de 25 céntimos y con 32 páginas de información ilustrada. Nació el 17 de noviembre de 1929 sin aclarar su ideología y se dejó de publicar el 11 de diciembre de 1938, también sin despedirse. Aunque de forma explícita no se posicionó políticamente, se la consideraba próxima a la izquierda republicana y apoyó al Frente Popular en las elecciones de 1936.

Durante los años en que se editó se puede observar una evolución tanto en los contenidos como en las portadas. En las primeras alternaba rostros femeninos del mundo de la farándula y el deporte con algunas fotografías de temas sociales que desarrollaba en el interior: "Raquel Meller en Madrid" (Crónica n 69) o "Amadeo Navarrete, ejemplo de niño héroe. Salvó la vida a otro niño, va al colegio y a las cinco de la mañana ya vende periódicos en Barcelona" (Crónica $n^{\circ}$ 68), ambas en 1931. Con el paso del tiempo, ya en 1936, las portadas se convirtieron en reclamos con las caras femeninas más bellas del momento obviando cualquier contenido periodístico: "Maruja Sanchiz, miss bañista más bella y miss teatro 1936" (Crónica $n^{\circ} 335$ ) o "Terry Walter, estrella de Hollywood" (Crónica n 348).

Los contenidos políticos, por tanto, fueron perdiendo peso desde la instauración de la República hasta que estalló la Guerra Civil, cuando se volvieron a retomar bajo un formato propagandístico. La página central con un desnudo femenino "artístico" se convirtió casi en seña de identidad de 
una revista que se presentaba como masculina y que compaginaba secciones de fútbol, toros y política con belleza, moda, espectáculos, reportajes curiosos y entrevistas a estrellas cinematográficas y artistas populares del momento. Crónica, una de las revistas líderes en el mercado publicitario fue pionera en la inclusión de páginas enteras de publicidad, publirreportajes y autopromoción: "Crónica, la revista más barata y popular de España. Por eso es la que más conviene a los anunciantes para obtener una publicidad eficaz" (Crónica 11-1-1931).

\section{Metodología.}

Las revistas de información general o magazines fueron los tipos de soporte con mayor difusión y popularidad entre la prensa no diaria (De Andrés, 2004) y por tanto hemos considerado que estos medios eran los que mejor podían ajustarse a la idea de escaparate social que mencionamos anteriormente.

Para el estudio se han seleccionado una serie de números que coinciden con dos períodos diferentes: el primero abarca del 4 de enero de 1931 al 12 de abril de 1931 y el segundo, desde el 5 de abril de 1936 al 12 de julio de 1936. La elección de las fechas, los meses previos a la declaración de la República y los últimos antes del estallido de la Guerra Civil, nos permite observar la evolución de la publicidad durante este período, tanto en número de inserciones, en variedad de marcas y productos como en el discurso publicitario. Así, se han cuantificado todas aquellas inserciones publicitarias aparecidas en los números seleccionados sin atender a su tamaño, siempre que el producto o la marca estuvieran claramente identificados y no se tratara de anuncios por palabras.

Posteriormente hemos establecido diez categorías donde se integran los diversos grupos sectoriales que aparecen representados en cada uno de los anuncios según el producto o servicio publicitados: a) Alimentación, b) salud, c) ocio y deporte, d) belleza e higiene (incluye productos relacionados con el sexo que no sean tratamientos de salud), e) hogar, f) automóviles y repuestos, g) moda y complementos, h) cultura, i) empresas de servicio y comercios y j) otros (aquellos que no se pueden incluir en ninguna de las otras categorías).

También se han establecido las siguientes variables para cada uno de los períodos analizados: productos según los sectores a los que pertenecen y según la procedencia del anunciante; inserciones publicitarias por sectores y por procedencia del anunciante y una comparativa de productos e inserciones entre los dos períodos analizados.

\section{Resultados}

El número de marcas anunciadas en la revista Crónica durante el período analizado de 1931 fue de 92 y cinco años después la cifra se había triplicado, con 257 marcas anunciadas. Esto denota la progresiva confianza del empresariado en el sector publicitario y la buena respuesta de los consumidores a un nuevo modelo de relación comercial. Pero si el incremento en el número de marcas fue espectacular, en el número de inserciones lo fue aún más. De los 340 anuncios que aparecieron en los quince números analizados de 1931 se pasó a 1.224 en el período de 1936, es decir, la cifra se multiplicó por 3,6. 
Que las inserciones crecieran proporcionalmente más que los productos anunciados indica que además de anunciarse nuevas marcas, las que ya lo hacían, repetían más de una inserción en cada número e incluso contrataban campañas para un cierto tiempo con anuncios diferentes en cada número. Es el caso del arroz Granito, de los Hermanos Ferrer, de Valencia, que protagonizó una de las primeras campañas publicitarias de calidad durante 1931 (curiosamente en el año 1936 había desaparecido de la revista Crónica):"Del arrozal a sus manos. Higiénico envasado. Saquitos precintados. Peso exacto. Primera calidad y regalos en el interior" (Crónica 11-1-1931)

En 1936 ya eran frecuentes las marcas que recurrían a campañas muy elaboradas, con páginas completas y diseños diferentes en cada una de sus inserciones como el jabón Heno de Pravia, el dentífrico Dens, los cosméticos Vaconcel, el adelgazante Gelée Mitza o el ejemplo siguiente, el reconstituyente Phoscao: "Phoscao, alimento fortificante para jóvenes anémicas que escapan de la tuberculosis en preventorios de montaña" (Crónica 7-6-1936) - página completa de una joven enferma en una habitación frente a montañas mientras otra joven le ofrece el producto-.

El sector que aglutinaba el mayor número de marcas anunciadas era el relacionado con la belleza, la higiene y los revitalizantes sexuales ( $26 \%$ en $1931 ; 34 \%$ en 1936). Le seguía el sector salud $(21,7 \%$ en 1931 y $20,2 \%$ en 1936) y las empresas de servicios y establecimientos comerciales (10,8\% en 1931 y $8,5 \%$ en 1936). La cultura apenas supone un $10 \%$ y el resto de sectores obtienen porcentajes inferiores al $7 \%$ en ambos períodos.

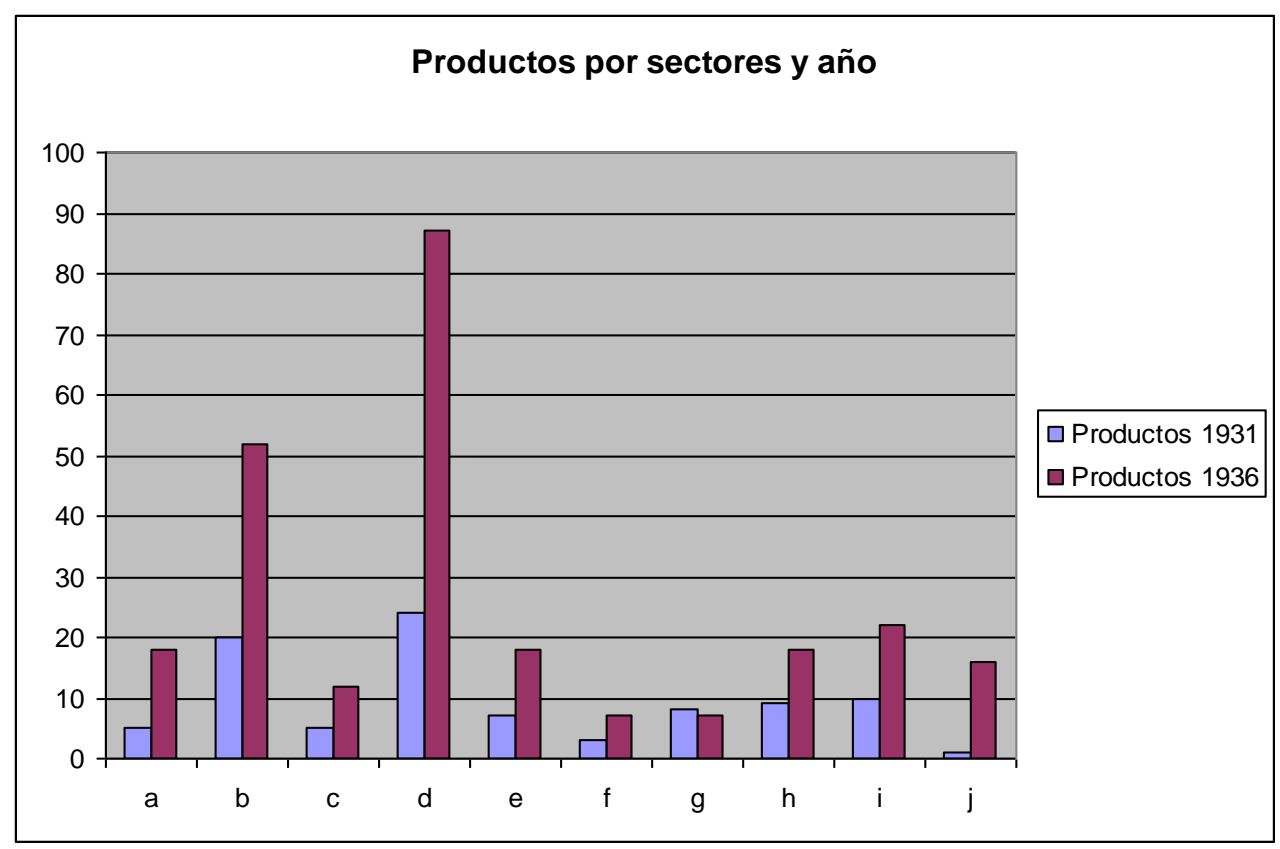

Fuente: elaboración propia Cuadro 1 


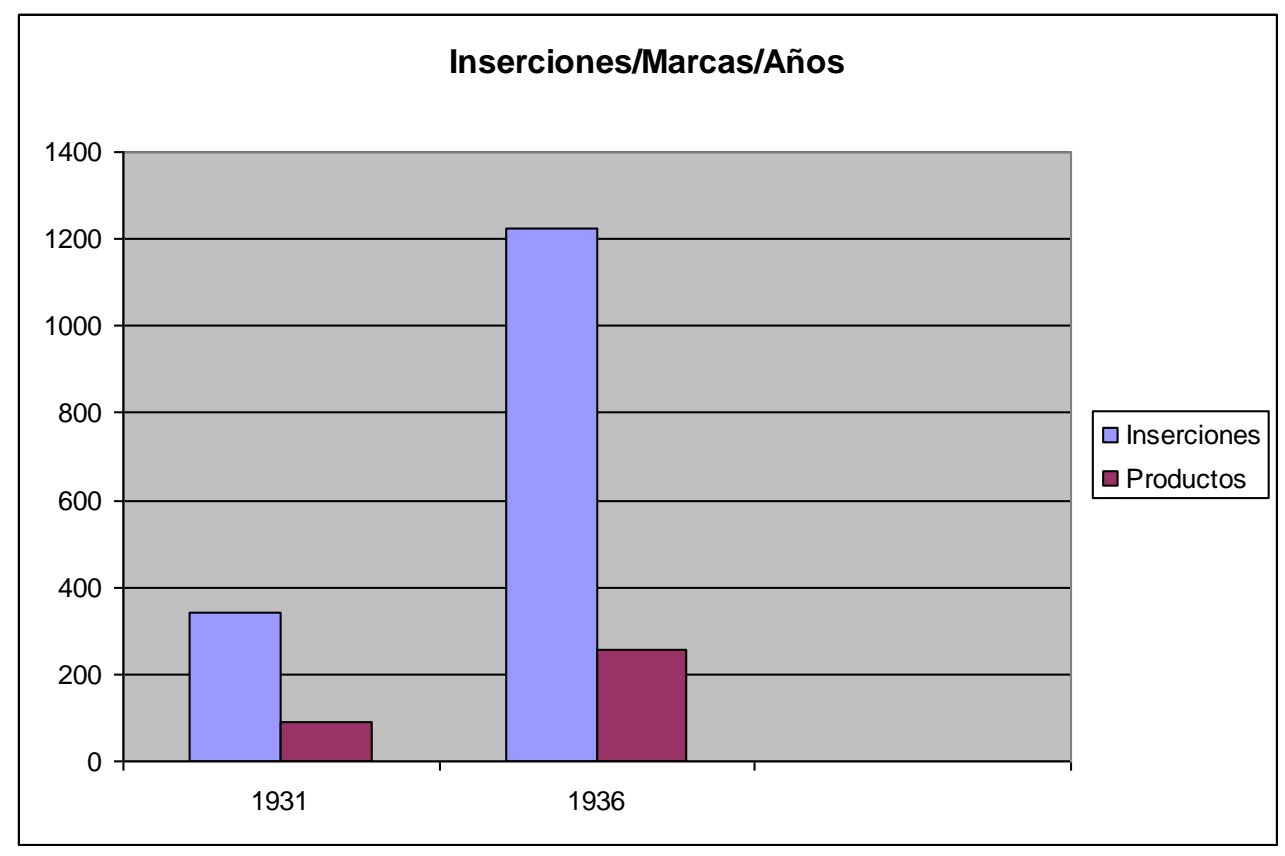

Fuente: elaboración propia

Cuadro 2

Extrapolando los datos resultantes de las gráficas anteriores, y asumiendo que sería posible describir un modelo de sociedad observando los productos que consume, parece que los españoles de la década de los treinta eran especialmente receptivos a la compra de productos para mejorar su aspecto físico y su salud, por este orden, a mucha distancia de productos de otros sectores, quizá más básicos y por ello menos publicitados, como la alimentación, la ropa y el hogar. No obstante, a medida que avanzan los años republicanos, los productos de salud van perdiendo fuelle. El sector más boyante, tanto en variedad de marcas como en número de inserciones es el de productos de belleza e higiene que continuó imparable su ascenso hasta que la guerra lo frenó en seco.

\section{1.- La salud}

Entre los productos más publicitados están los remedios contra las enfermedades venéreas, ("Cachets del dr. Soivré y Grágeas del dr. Soivré) que lideraban el ránking de inserciones en 1931. En 1936, los productos del doctor Soivré continuaban en lo más alto de esta lista, pero iban apareciendo más variedad de productos similares, que bajo el nombre de "Urinarias", vendían soluciones para las mismas dolencias. Todo indica que los españoles de entonces padecían muchas enfermedades de transmisión sexual, que en 1931 se disfrazaban tras conceptos más púdicos como de "vías urinarias" pero que en 1936 pasaron a denominarse por su nombre técnico: blenorragia.

Los males estomacales y pulmonares, tos, tuberculosis, anemias, dolores musculares, de pies, y una variada colección de enfermedades nerviosas debían ser frecuentes si atendemos a la gran cantidad de marcas de ese tipo de remedios que aparecen en todos los números. Otros de los productos estrella en los números analizados en 1936 son las supuestas "píldoras abortivas" 
según se desprende del texto publicitario, aunque en ningún momento aparece el término "aborto", ni su composición. Las Perlas Femi, Fortan, Chaves, Victoria, Foredal o Trietante tenían abastecido el mercado de este misterioso producto que manejaba a su antojo la menstruación.

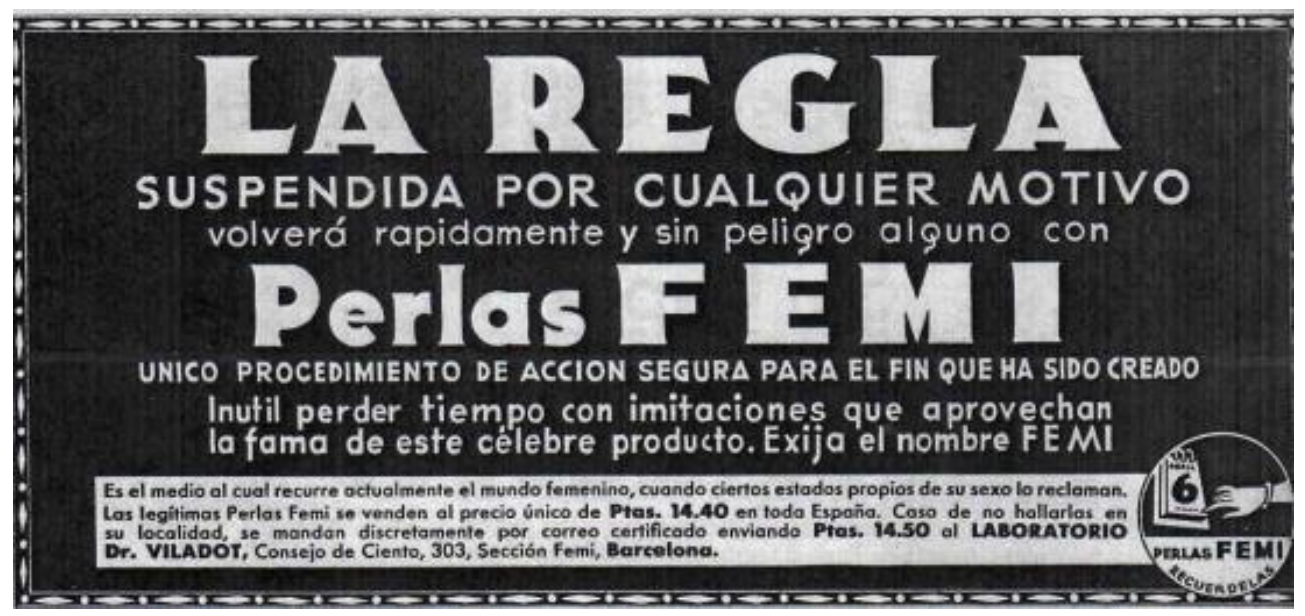

Fuente: Revista Crónica, 1936

Los remedios para curar el alcoholismo también aparecían ampliamente publicitados, aunque socialmente no se consideraba una enfermedad, si no un vicio. Los textos de los anuncios no dejaban lugar a dudas: "Borrachos. Curación segura del vicio. No se enteran ni perjudica. Mandamos información reservada gratis. Clínica Basté. Barcelona"

\section{2.- La belleza}

El concepto de belleza femenina vigente durante los años de la República se diferencia muy poco del estereotipo de ideal femenino que persiste en la actualidad y que Carrillo Durán (2003) retrata como una mujer atractiva, delgada, autosuficiente, libre y segura de sí misma. No obstante, a pesar de que Carrillo sitúa ese cambio de tendencia hacia la delgadez como símbolo de éxito social a principios de la década de los sesenta en España, en las postrimerías del período republicano, la publicidad ya apostaba firmemente por ese nuevo modelo social de percepción de la belleza.

En 1931 el estereotipo de mujer que aparecía en la publicidad de productos cosméticos aún se correspondía con jóvenes de formas redondas y pieles extremadamente blancas. De ahí, que innumerables productos aclaradores de la tez como la Cera Aseptina se anunciaran prometiendo una cara "tres tonos más clara en tres noches". En 1936, sin embargo, los gustos comenzaban a evolucionar hacia la delgadez y las pieles bronceadas: "Con Nivea al aire y al sol, su piel se hace flexible y ya no se seca. Usted protege la piel y se defiende de las quemaduras del sol. Usted tomará mejor color moreno y su aspecto será el que dan los deportes".

Este revolucionario concepto de belleza sustituía la piel oscura, identificada tradicionalmente con las clases más pobres que trabajaban al sol, por la piel morena como símbolo de una clase acomodada que puede disfrutar de vacaciones en la playa, en la montaña o realizar deportes al aire libre. Las corrientes higienistas que circulaban por Europa, el culto al deporte que institucionalizaron todos los regímenes dictatoriales del momento y las imágenes que el "star 
system" americano distribuía desde las playas californianas empezaban a cambiar los referentes estéticos que la publicidad supo explotar tan bien.

Los anuncios publicitarios presentados bajo formato de noticias, dirigidos a un público no demasiado adiestrado en diferenciar los mensajes periodísticos de los publicitarios, eran frecuentes en la época. Ésta era una manera atractiva de presentar las novedades de los productos aunque su eficacia respecto a la consecución de los objetivos sea bastante variable (Bandrés, 2010). No obstante, esa discriminación entre ambos conceptos, hoy perfectamente disociados, no aparecía tan clara en esta fase inicial de las técnicas publicitarias que entendían los anuncios como un proceso informativo con las exageraciones propias de su naturaleza y los fines para los que habían sido creados (Ferrer, 1997). Así, los productos Risler se publicitaban bajo un falso formato informativo, con un texto publicitario que presentaban como "caso real":

"El anuncio del diario decía "Falta secretaria particular inteligente". Se presentaron unas 50 a concurso y sin examinar sus aptitudes fue elegida la señorita Sador como secretaria particular del financiero Roberto Hallen, quien confesó que la hermosura de su secretaria le había captado su voluntad, eclipsando a las demás aspirantes. Y se da el caso más célebre aún, de que hoy se hecho público el próximo enlace del Sr. Hallen con la Srta. Sador, su secretaria, cuya belleza le ha prendido en las redes amorosas y formales del matrimonio. Interwiuada la Srta. Sador, ha declarado que debe su hermosura al uso constante de los Productos de Gran Belleza RISLER que empleó por primera vez 2 días antes de presentarse como aspirante a secretaria y que seguirá usándolos toda su vida para conservar su belleza y la ilusión de su esposo(...)"

El recurso a los testimonios, tanto de personajes conocidos de la época como de consumidores anónimos, que tan buenos resultados le habían dado a la agencia norteamericana J. Walter Thompson desde los años veinte (De Andrés, 2004) fue una constante en la publicidad española de la República, especialmente en los productos de belleza como la crema adelgazante GeléeMitza que fue una de las primeras en incorporar testimonios de personajes populares:

"Declaro franca y espontáneamente que debo mi triunfo al maravilloso producto de uso externo para adelgazar Gelée-Mitza, pues me han sido necesarios solamente dos únicos meses de tratamiento para que mi esbeltez sobresaliera y lograra el más preciado título para una mujer. Natalia Farré, Miss Cataluña 1936"

Entre los productos estrella también se encontraban perfumes, jabones, depilatorios, tintes para el cabello, lápices de labios, cremas para cara y manos, dentífricos, champús, esmaltes de uñas, desodorantes, bronceadores o clínicas estéticas. Incluso la Cafiaspirina, una marca de populares pastillas contra el dolor, basaba su discurso publicitario en la belleza más que en la salud: "El dolor envejece (...) $\mathrm{Ni}$ el hombre más fuerte los resiste sin que en su semblante se reflejen profundas huellas, que afean y envejecen. Pero hay un remedio. Un remedio maravilloso: Cafiaspirina"

Si bien es cierto que la mayoría de estos productos tenían como destinatario el público femenino, el hombre también se iba incorporando al mercado de productos de belleza a pasos agigantados. Se percibía a través del continuo incremento de afeites masculinos como la colonia Floïd, Gong o Varón Dandy, hojas y maquinillas de afeitar Gillete, fijadores de pelo, lociones anti-calvicie y tintes para las canas. La imagen del hombre peludo, con largas barbas, entrado en años y en carnes se estaba transformando en algo parecido a lo que hoy denominaríamos "metrosexuales". Y no sólo se percibía a través de la publicidad, sino también por los titulares de prensa, como éste que firmaba el periodista de Crónica, José L. Barberán: 
"El mundo al revés. Actualmente, en las peluquerías donde se ondula, riza y oxigena, el mayor contingente de parroquianos lo dan los hombres...Y por ello, sin duda en justa reciprocidad, los sastres confeccionan de día en día mayor número de trajes masculinos para la mujer" (Crónica $\mathrm{n}^{\circ}$ 337)

Este esmero en el cuidado de la imagen personal de los varones también se observaba en el aumento de anuncios de establecimientos de moda masculina como la camisería Samaral o la sastrería Novales de Madrid. Pero si había un tema que preocupaba a los hombres, a tenor de la profusión de anuncios, era el de la virilidad. "Hombres agotados"“Hombres débiles" "Fuerza viril integral" rezaba en los eslóganes publicitarios de productos como las tabletas de vida GRAFF o el tratamiento radioactivo EPIRTAR que "sin inyecciones ni injertos restablece la fuerza sexual y rejuvenece a la infinidad de seres decaídos, impotentes y prematuramente envejecidos...". Este tratamiento también tenía una versión femenina denominada DORFEAR.

\section{3.- El hogar, la familia y el trabajo}

Aparatos de radio, máquinas de coser y de escribir, cámaras fotográficas, fonógrafos y ventiladores no podían faltar en un hogar urbano de clase media-alta, proclamaba la publicidad desde las páginas de las revistas. Los sistemas de pago a plazos se incluyen en la mayoría de los anuncios ya que muchos de los productos resultaban inasequibles para gran parte de las familias sobre todo en años de recesión económica internacional. En 1931, la empresa Créditos S. Loynaz, de San Sebastián, se especializó en la venta a plazos de artículos de lujo como fonógrafos, colecciones de discos, vajillas o joyas, al precio de diez pesetas al mes ${ }^{1}$. En 1936, este tipo de facilidades se extendió a la mayoría de artículos que, por su elevado precio, eran inaccesibles para el consumidor medio, como automóviles o cámaras fotográficas. Uno de los sectores donde más rápidamente se hizo visible la crisis fue en el automovilístico que redujo el tamaño de los vehículos y cambió el discurso publicitario: los coches de lujo empezaron a compartir espacio con los utilitarios pagados a cómodos plazos.

La gran diferencia de clases existente entre los consumidores se percibía, además de por el tipo de producto anunciado, por el tamaño y creatividad del propio anuncio. Un ejemplo bastante descriptivo es el de los artículos pensados para hogares de clases altas frente a los de las clases trabajadoras. Mientras páginas enteras mostraban sofisticadas ilustraciones de cuartos de baño de la Compañía Roca y de mobiliario londinense de la Compañía de Muebles y Decoraciones S.A., otros anuncios más modestos, tanto en diseño como en espacio, promocionaban raticidas, insecticidas y anti-carcomas para los hogares de las clases menos pudientes.

La publicidad representaba a una familia española con tres o cuatro miembros como máximo. Se trataba de un nuevo tipo de familia nuclear que comenzaba a arraigar en las zonas urbanas, producto de las migraciones interiores campo-ciudad, que simbolizaba la modernidad $y$ representaba mejor que nada el éxito de la planificación familiar que se estimulaba desde el Gobierno. Productos como el conocido Phoscao alternaba la imagen de la madre y el hijo con la de la unidad familiar al completo, aunque no se ha observado ningún caso donde aparezca exclusivamente el padre alimentando o administrando medicinas al hijo. Productos de salud como los Hipofosfitos, en cuyos anuncios solía aparecer el estereotipo familiar de la época, recurrían a imágenes infantiles sólo para representar el raquitismo o la inapetencia. La Lechera era otra de las marcas que recurría frecuentemente a la composición materno-infantil para su publicidad cuando se anunciaba como el mejor complemento de la lactancia; sin embargo, cuando vendía el producto como una exquisitez para el paladar, utilizaba la imagen de una criada con cofia. 
Los niños no fueron protagonistas de los anuncios hasta bien avanzado el período republicano. Las campañas de escolarización, la lucha contra la mortalidad infantil y el empeño de las instituciones sanitarias para que la población, sobre todo la infantil, adquiriera hábitos de higiene comenzaron a situar poco a poco a los niños en el primer plano de la estructura familiar.
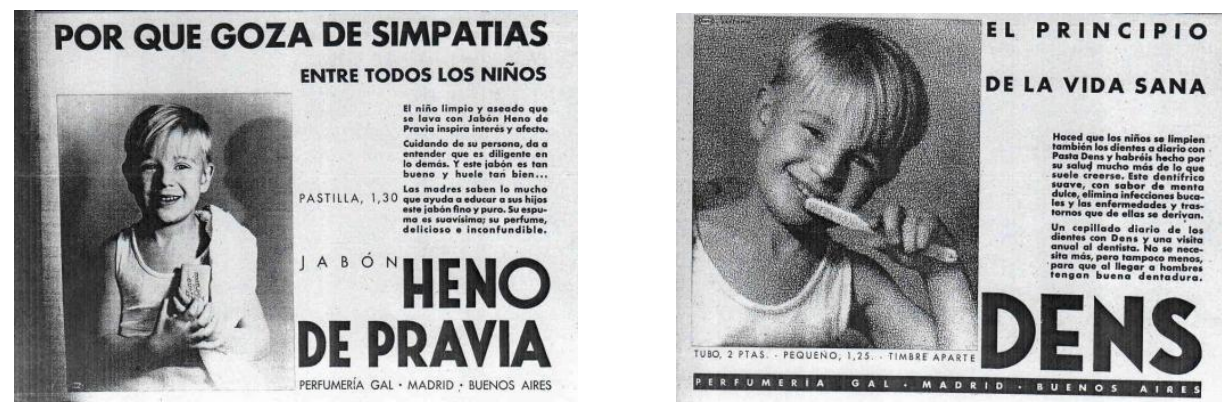

Fuente: revista Crónica 1936

No obstante, en los números analizados de la revista Crónica no hemos observado ningún anuncio de productos básicamente destinados a la población infantil, como juguetes o ropa (los chocolates y galletas se publicitaban como exquisiteces para adultos). Fue en el sector de los productos de higiene personal donde debutaron los niños como protagonistas. La campaña escolar del dentífrico DENS, de la agencia Veritas para la empresa Gal, enseñaba cómo se debían limpiar los dientes. Otras marcas como Camomila Intea, que en 1931 se dirigía a un público adulto femenino, en 1936 ya incluía a niños como protagonistas exclusivos en los anuncios.

La publicidad representaba a la población masculina como ejecutivos, empresarios o profesionales liberales. Los trabajos con más proyección de futuro, según el discurso publicitario, eran los relacionados con el sector de los medios de comunicación como técnicos de radio, televisión y películas sonoras, que se promocionaban a través de cursillos a distancia. La intensa actividad laboral masculina era uno de los argumentos publicitarios más repetidos, adelantándose en varias décadas a los estereotipos actuales de una población estresada:

"El agotamiento a muchos de nosotros casi nos parece un estado normal. Con la intensa vida de los negocios que llevamos, queremos tener nuestras distracciones, aunque a veces es a costa de nuestra salud. Evite que un decaimiento general se apodere de Vd. Despeje su cerebro y haga revivir sus fuerzas vitales tomando 2 tabletas de CAFIASPIRINA"

Las mujeres, en cambio, aparecían representadas mayoritariamente como amas de casa o como chicas jóvenes y solteras que trabajaban de secretarias, dependientas o peluqueras. A ellas se dirigía gran parte de la publicidad de cosméticos como fórmula para conseguir o mantener su empleo de manera mucho más eficaz que la formación. Para aguantar ese frenético ritmo de vida se anunciaban gran variedad de reconstituyentes "nervo-sexuales" como OKASA o EPIRTAR, para que el agotamiento no les inhibiera el deseo sexual. Comenzaba a venderse la imagen de la "super-woman" en su triple papel de madre, trabajadora y amante: 
"La vida rápida. Por tres pesetas, todo incluido, puede usted tomar en menos de $1 / 4$ de hora, huevos, pescado y carne servidos en un monumental plato con pan y vino...como estas muchachas que sin tiempo para ir a sus respectivas casas, comen en pocos minutos en los bares americanos" (reportaje publicado en Crónica n³36).

La crisis, no obstante, comenzaba a dejarse ver con la aparición de empresas de cobros a morosos, con la proliferación de anuncios para atraer la suerte y la invitación a comprar lotería. "Hay que airear el dinero. Las crisis económicas no se resuelven guardándolo bajo siete llaves", decía el texto publicitario de 1936 donde se animaba a participar en un sorteo especial para financiar la Ciudad Universitaria de Madrid.

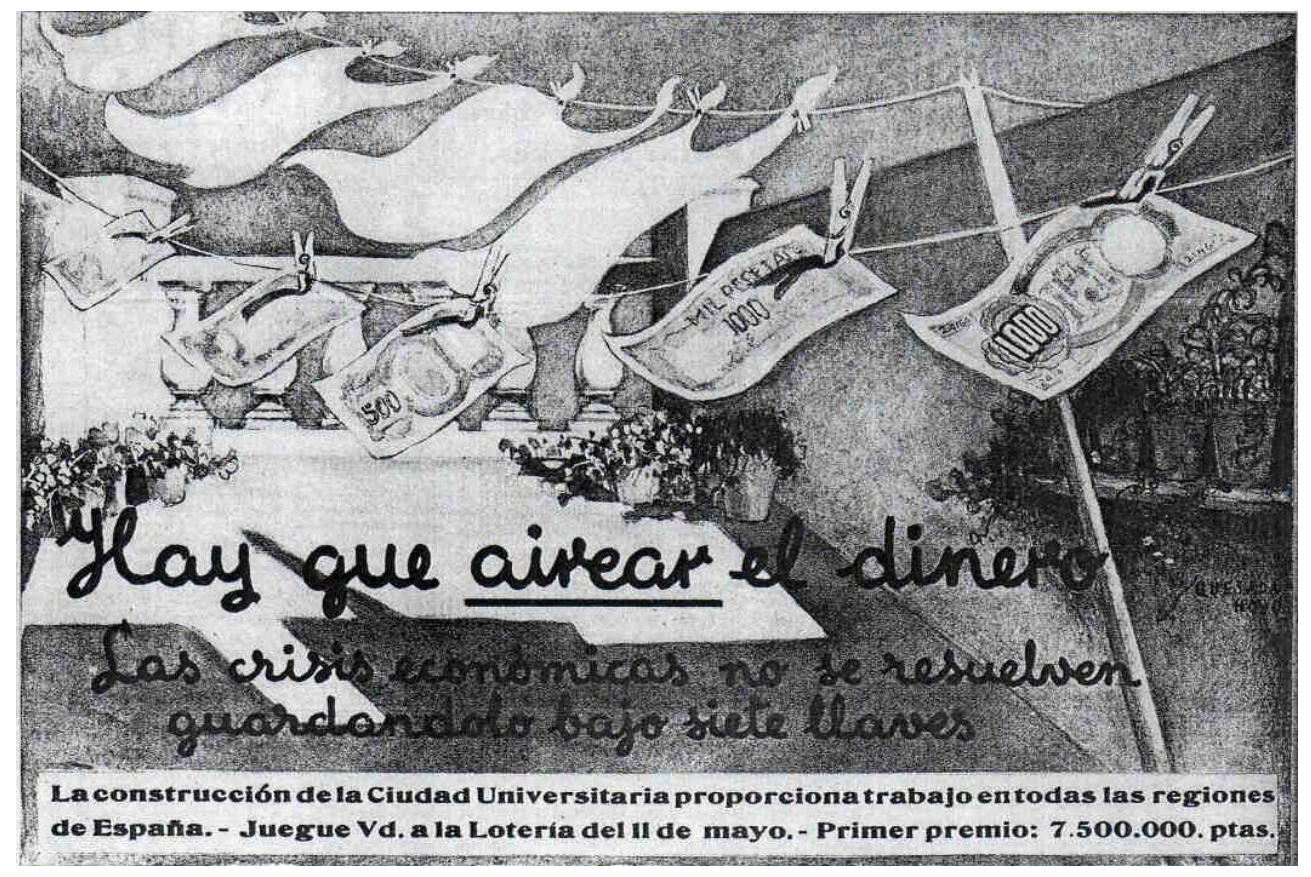

Fuente: Revista Crónica, 1936

\section{4.- Mujeres y hombres}

La publicidad se mantenía a caballo entre los dos modelos de mujer que convivían en la España de los años treinta. Así podemos encontrar un estereotipo, representado por amas de casa o jóvenes asalariadas que aspiran a encontrar marido a las que se dirigen la mayoría de los anuncios de cosméticos que refuerzan valores como la belleza o la pulcritud asociados tradicionalmente al sexo femenino.

También la función maternal era un lugar común en la publicidad de la época, sobretodo en anuncios de productos alimentarios o de salud.

La figura femenina como reclamo sexual para la venta de productos destinados al varón comenzaba a fraguarse en el sector automovilístico y en 1931 marcas como Fort Dunlop incluían en sus anuncios de neumáticos a bellas mujeres junto a la rueda de un coche, cuando era evidente que ninguna de ellas se disponía a cambiar la pieza. Sin embargo, la publicidad no descuidaba un modelo emergente de mujer, con mayor poder adquisitivo y gustos más sofisticados, que deslumbradas por el reciente protagonismo femenino en campos como la 
política, las artes o el deporte, trataban de desligarse del papel que tradicionalmente se les había adjudicado.

Para Sánchez Aranda (2003: 76) la mujer no alcanza la madurez como destinataria de la publicidad hasta los años ochenta cuando "deja de aparecer como copiloto en los anuncios de vehículos para ser ella la que tome el volante de su propio automóvil, se acerca a los bares para disfrutar de bebidas alcohólicas en compañía de un grupo de amigos, cuelga el delantal y se viste con vaqueros y ropa deportiva". No obstante, hemos comprobado cómo en la década de los treinta la figura femenina comenzó a aparecer en los anuncios practicando deporte, bailando en la playa, conduciendo un automóvil, fumando o disfrutando de una intensa vida social sin compañía masculina.

Los modelos publicitarios masculinos evolucionaban desde la imagen de un hombre maduro, con sobrepeso, bigote, barba y canas hasta un nuevo varón joven, delgado, pulcro y cosmopolita, valorado en función del éxito de sus negocios. Echando un vistazo a la publicidad del período republicano parece que no existieran obreros ni campesinos sino sólo ejecutivos o empleados de cuello blanco que debían presentar un aspecto cuidado para agradar por igual a las mujeres y a los clientes.

Sin embargo, lo que en la mujer se vende como productos de belleza, para los hombres, esos mismos productos, se consideran de higiene personal. La exaltación de la belleza masculina aún no había entrado de pleno en los manuales publicitarios y se disfrazaba tras otros conceptos como juventud y virilidad. De ahí la gran cantidad de lociones para el afeitado, perfumes, tintes y productos estimulantes y potenciadores sexuales. Aunque coexisten cronológicamente, entre el varón decimonónico que anuncia el tratamiento del Dr. Soivré contra la blenorragia y el joven que anuncia la colonia Varón Dandy existe una brecha social que la publicidad supo reflejar muy bien.

Las relaciones entre ambos sexos atravesaban también un período convulso. La equiparación legal de la mujer al varón, la lenta pero progresiva incorporación de las mujeres a la vida laboral, la aprobación de leyes como el divorcio y la relajación en las normas de la moral tradicional cristiana en lo referente a comportamientos sexuales, situaron al hombre en un terreno desconocido hasta el momento, en el que se sentía inseguro por el nuevo papel que le tocaba jugar. Reflejo de esta crisis de identidad masculina es la búsqueda de nuevos modelos de virilidad sustentados sobre iconos cinematográficos que ayudaban a vender marcas con el objetivo de hacer atractivo al varón ante una nueva mujer emancipada, legal y socialmente, que podía elegir libremente a su pareja.

Así, en 1936, aparecen los primeros anuncios de preservativos "irrompibles, esterilizables y con garantía para cinco años" importados de Estados Unidos. Y aparecían no sólo en revistas de información general como Crónica, sino también en revistas femeninas como Estampa, en lo que parecía un guiño a las políticas de planificación familiar estimuladas por el Gobierno y una apuesta clara por la disociación entre sexo y maternidad. Las revistas incluían cada vez más fotografías y dibujos con atrevidos desnudos femeninos; se publicitaban enciclopedias sobre el "arte de conservar el amor sexual en el matrimonio" y libros para evitar el embarazo de una "manera científica" donde se informaba que las mujeres sólo son fértiles unos pocos días al mes.

\section{5.- El ocio y la cultura}

El cine fue la referencia cultural de los españoles durante los años de la República. Con la reciente aparición de las películas sonoras, el público se hizo asiduo de las salas cinematográficas 
lo que provocó una importante crisis en el teatro y en los espectáculos de variedades de la época. Los artistas de revista españoles exigían cuotas para sus espectáculos en los intermedios de las películas o que se fijaran unos días a la semana para que los teatros sustituyeran las proyecciones cinematográficas por los tradicionales espectáculos de variedades.

El "star system" americano provocó la sustitución de las tiples y vicetiples autóctonas por estrellas cinematográficas extranjeras como referentes estéticos. Las portadas de las revistas que en 1931 mostraban a artistas como Gloria Guzmán o Raquel Meller fueron cambiando hacia otras bellezas, mayoritarias en las portadas de 1936, como Grace Poggi o Margot Grahame, calificadas todas como "bellos rostros cinematográficos".

La cartelera cinematográfica no era objeto de la publicidad porque se incluía en los espacios informativos o en los anuncios clasificados de la prensa diaria, por eso sorprende la gran campaña publicitaria de la película "Rebelión a bordo" de Metro Goldwyn Mayer que, con anuncios en páginas completas, apareció en cinco números consecutivos de la revista Crónica en 1936. La promoción incluía armar un rompecabezas con distintos fragmentos del cartel de la película y un concurso para encontrar la frase más ingeniosa con la que publicitar la película en España

El turismo también empezaba a arrancar con fuerza. Cruceros por el Mediterráneo, por el Atlántico Norte o viajes en barco a Nueva York eran los principales reclamos publicitarios de la empresa alemana Nurddeutscher Lloyd, con sede en Madrid, que se anunciaba en 1931. Algunos establecimientos franceses como el hotel Mariette Pacha de Marsella, la brasserie Albert's y el hotel Majestic de Barcelona también se anunciaban en Crónica. En sus páginas aparecían viñetas en las que se ironizaba sobre el turismo argumentando lo fácil que era conseguir un billete para las cataratas del Niágara, el cañón del Colorado o los fiordos y la dificultad para comprar un billete a Guadalajara. Este afán por descubrir el mundo queda también reflejado en la aparición publicitaria de nuevos productos como cámaras fotográficas vendidas a plazos, diferentes tipos de películas y establecimientos para revelar fotografías.

Los años treinta fueron los comienzos del concepto vacaciones no sólo para las clases sociales altas sino también para las incipientes clases medias urbanas que no podían embarcarse en cruceros pero sí acceder a destinos más asequibles. Éste es el caso de las campañas turísticas de Estoril y de Cádiz que aparecen en los números analizados de 1936. 


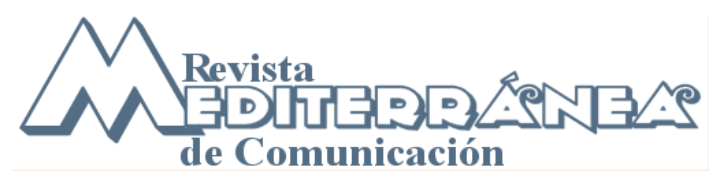

ISSN 1989-872X - Año 1(2010), pp. 195-212

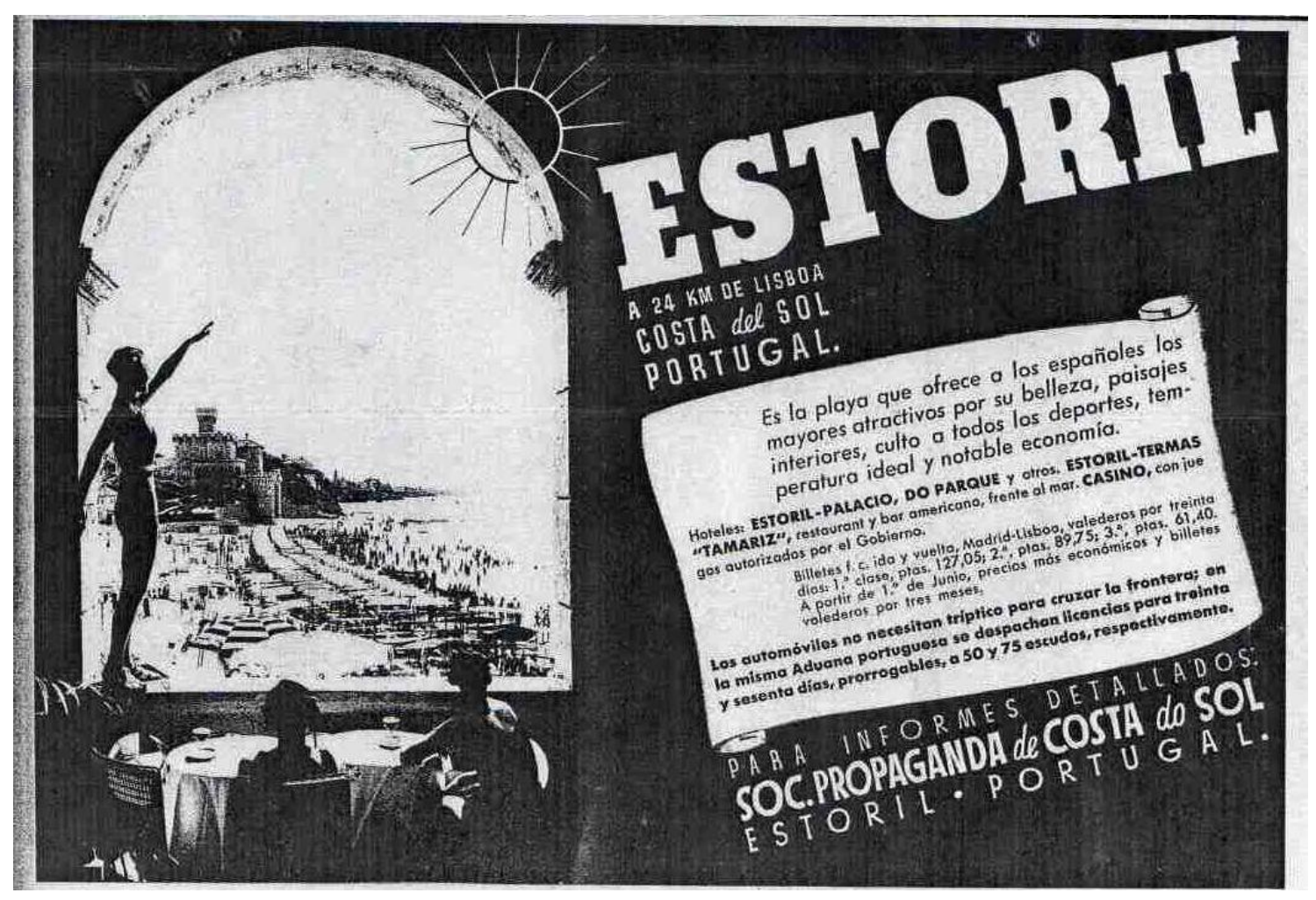

Fuente: revista Crónica 1936

Con las vacaciones llegaron la playa, la vida al aire libre, la práctica de deportes y un sinfín de marcas que anunciaban productos para protegerse del sol y alcanzar rápidamente el bronceado que tan de moda se había puesto entre las clases urbanas. La mayoría de estas marcas incluían en sus textos publicitarios las instrucciones de uso, lo que indica la novedad de la mayoría de los productos. Las modelos publicitarias dejaban ver sus cuerpos sobre la arena, lo que no volvió a suceder en España hasta entrados los años sesenta.

\section{6.- La geografía de la publicidad}

La industria de bienes de consumo, a la que pertenece la mayoría de los productos anunciados en publicidad, estaba situada en Cataluña, Madrid, País Vasco y Comunidad Valenciana. En 1931, el $34 \%$ de los anunciantes de la revista Crónica provenía de Cataluña, el 22\% de Madrid, el 6,6\% del País Vasco y el 5,5 de la Comunidad Valenciana, aunque en 1936 los anunciantes se concentraban fundamentalmente en el eje Madrid-Barcelona. En el último período analizado casi la mitad de los anuncios sólo incluyen el producto y la marca pero no el anunciante. Éste era un síntoma de que la publicidad se asentaba, ya que cuanto más conocida es una firma menos necesita decir de ella misma y sólo cabe reforzar el recuerdo y la imagen de marca. Entre los anunciantes cuya procedencia geográfica sí consta, el 31,5\% se situaba en Cataluña, el 17,5\% en Madrid, y el resto de comunidades autónomas tienen una aparición puramente testimonial.

Lo mismo ocurre en cuanto al volumen de inserciones según la procedencia del anunciante. En 1931, los anunciantes catalanes eran los que más confiaban en las técnicas publicitarias para dar a conocer sus firmas o productos, con un $36,8 \%$, seguido de los madrileños, con un $20,2 \%$, los valencianos con un $8,8 \%$ y los vascos, con un 5\%. En 1936, el $34 \%$ de las inserciones publicitarias tenían como origen un anunciante radicado en Cataluña, el 14,6\% eran empresas 
madrileñas y con porcentajes inferiores al 3\% estaban los anuncios de empresas asturianas, valencianas y vascas.

\section{Conclusiones.}

La publicidad es un poderoso instrumento de socialización, un espejo mágico donde las sociedades se reflejan, a veces como son, y siempre como desearían ser. La España del período republicano que recrea la publicidad de la época se corresponde más con una visión idealizada de sí misma como sociedad moderna y urbana que con la imagen, más ajustada a la realidad, de un país mayoritariamente rural y tradicional en sus usos y costumbres.

La publicidad presenta un modelo vanguardista de sociedad extremadamente preocupada por la estética y la salud, que habita en zonas metropolitanas, donde los hombres trabajan como ejecutivos y las mujeres como empleadas del sector servicio o amas de casa. Sus referentes sociales son el "star system" americano que llega a las pantallas cinematográficas y relega a espectáculos autóctonos como las revistas de variedades.

Otro lugar común de la sociedad de la II República es la sobrevaloración y explicitación del sexo. La desmesurada oferta de productos contra las enfermedades venéreas y de estimulantes sexuales, amén de libros ilustrados con desnudos y enciclopedias para aprender técnicas sexuales, describe una sociedad en proceso de liberación de la rígida moral católica que la caracterizaba. En cuanto a los estereotipos masculino y femenino, ambos transitan entre un modelo tradicional y otro innovador donde los roles comienzan a difuminarse. Así la mujer aparece atada al mundo de lo privado ejerciendo de esposa y madre, pero también lo hace como una mujer libre, que trabaja, viaja, hace deporte y comparte su tiempo de ocio con el hombre en condición de igualdad. Los nuevos varones que incorpora la publicidad al imaginario social siguen dominando el terreno de lo público como hombres de negocios aunque comienzan a asumir roles hasta entonces femeninos, como la higiene personal, la belleza o el cuidado de los hijos.

La familia que retrata la publicidad se ajusta al modelo nuclear, con pocos miembros, paulatina incorporación de la presencia del padre en el hogar y con un lento pero firme ascenso del papel de los niños dentro de la estructura familiar.

Si se incorporara el color a los diseños publicitarios y se cambiara la ilustración por la fotografía, se observarían pocas diferencias entre la publicidad de la España de los años treinta y la actual, ya que el modelo de sociedad que representaban, salvando todas las distancias, sigue siendo esencialmente el mismo. La guerra y la dictadura sólo fueron un largo paréntesis.

\section{Referencias bibliográficas.}

Alonso, L.E/ Conde, F (1994): Historia del consumo en España: una aproximación a sus orígenes y primer desarrollo. Madrid: Debate

Bandrés Goldáraz, E (2010): “Mejorar la información: uso del lenguaje publicitario en las noticias audiovisuales" Revista Mediterránea de Comunicación. Año 1, pp 173-194 (on line) http://www.rmedcom.org/2010/10BandresGoldaraz.pdf (consultado el 13-10-2010) 
Carrillo Durán, M.V (2003): "La transmisión de valores sociales por medio de las imágenes. La identificación de la mujer delgada igual a mujer triunfadora en la población adolescente" en Comunicación y Sociedad, vol XVI, no 2, pp 33-47

De Andrés del Campo, S (2004): "Estereotipos de género en la publicidad de la Segunda República española: Crónica y Blanco y Negro". Tesis doctoral. (on line) http://www.ucm.es/BUCM/tesis/inf/ucm-t26350.pdf (consultado el 15-10-2010)

De Gabriel, N (1997): "Alfabetización, semialfabetización y analfabetismo en España (1860-1991)" (on line) http://dialnet.unirioja.es/servlet/articulo?codigo=150211 (consultado el 15-10-2010)

Fagoaga, C/ Secanella, P (1984): Umbral de presencia de mujeres en la prensa española. Madrid: Instituto de la Mujer, Ministerio de Cultura.

Ferrer, E. (1997): Información y Comunicación. México: Fondo de Cultura Económica.

Goffman, E. (1991): Los momentos y sus hombres. Textos seleccionados y presentados por Yves Winkin. Barcelona: Paidós

Merron, J (1999): "Putting Foreign Consumers on the Map: J. Walter Thompson's Struggle with General Motors' International Advertising Account in the 1920s" en Business History Review, $n^{\circ}$ 73, pp 465-503

Núñez Pérez, G (1989): Trabajadoras en la Segunda República. Un estudio sobre la actividad económica extradoméstica (1931-1936). Madrid: Ministerio de Trabajo y Seguridad Social

Otero Carvajal, L.E (2003): "Ocio y deporte en el nacimiento de la sociedad de masas. La socialización del deporte como práctica y espectáculo en España en el primer tercio del siglo XX" en UCM. Cuadernos de Historia Contemporánea no 25, pp.169-198. (on line) http://www.ucm.es/info/hcontemp/leoc/deporte.htm (consultado el 14-10-2010)

Rodríguez Martín, N. (2008) "Los inicios de la prensa publicitaria en España. Las revistas empresariales" en IV Congreso Internacional de Prensa y Periodismo Especializado. Historia y realidad actual. Departamento de Historia de la Comunicación Social. UCM. As. de la Prensa de Guadalajara. Guadalajara 7-9 de mayo. (on line) http://www.ucm.es/info/hcontemp/leoc/taller/publicidad.pdf (consultado el 15-10-2010)

Rubio Benito, T. (1990): "Terciarización de la población activa en España" en Espacio, Tiempo y Forma. Serie VI, Geografía. t 3 pp 41-54

Sánchez Aranda, J (2003): "La publicidad y el enfoque de la imagen femenina" en Comunicación y Sociedad, vol. XVI, n 2, pp 67-92

Zoido Naranjo, F/ Arroyo Pérez, A (2003): La Población en España. Tendencias Demográficas Durante el Siglo XX en España. Madrid: INE. Vol. 1. pp. 17-75 (on line) http://www.ine.es/prodyser/pubweb/tend_demo_s20/poblacion.pdf (consultado el 13-10-2010)

\footnotetext{
${ }^{1}$ Para poder valorar la oferta de Créditos Loynaz, conviene conocer que el jornal medio de un obrero en 1930 era de 9,59 pesetas diarias
} 